\title{
ANÁLISES FÍSICAS E MECÂNICAS DE ARGAMASSAS DE CIMENTO PORTLAND COM AREIA CONTENDO CINZAS DA QUEIMA DO BAGAÇO DE CANA-DE-AÇÚCAR COMO AGREGADO MIÚDO
}

\section{Luiz M.A. Cavalcanti ${ }^{1}$}

\section{Daniel V. Ribeiro}

RESUMO: O presente trabalho tem como objetivo avaliar o potencial de utilização da areia contendo cinza do bagaço da cana-de-açúcar (CBCA) em substituição parcial ou total ao agregado miúdo convencional para a produção de argamassas. Busca-se, assim, uma alternativa ambientalmente adequada para destinar-se esse rejeito e agregar valor a este sub-produto gerado pela indústria sucro-alcooleira. A areia contendo CBCA utilizada neste trabalho substituiu o agregado miúdo convencional nos teores de $25 \%, 50 \%, 75 \%$ e $100 \%$. Inicialmente, caracterizou-se fisicamente a areia contendo CBCA e moldaram-se corposde-prova com diversos teores de substituição, que foram analisados quanto às suas propriedades físicas (porosidade e densidade aparentes e absorção de água por capilaridade) e mecânicas (resistência à flexão e à compressão axial). Os resultados obtidos mostraram que a cinza possui indícios de propriedades pozolânicas, aumentando a resistência da argamassa nas idades mais tardias e mostrando excelente potencial para utilização na construção civil.

Palavras-chave: Argamassas. Cinzas. Bagaço de cana. Desempenho. Propriedades.

\footnotetext{
${ }^{1}$ Universidade Federal da Bahia - luizinho cavalcanti@hotmail.com

${ }^{2}$ Universidade Federal da Bahia - verasribeiro@hotmail.com
} 


\section{INTRODUÇÃO}

A busca por fontes de energias renováveis é uma tendência mundial. Neste sentido, a indústria sucro-alcooleira vem expandindo sua produção, com destaque para o álcool etanol. O Proálcool, Programa Nacional de Álcool, é o maior programa comercial de utilização de biomassa para a produção de energia no mundo e representou uma iniciativa de substituição de derivados de petróleo no setor automotivo, através do uso do álcool como combustível único nos veículos. Resolveu, também, o problema da octanagem da gasolina, substituindo o chumbo tetraetila, prejudicial à saúde humana.

Atualmente, a cana-de-açúcar é tratada como uma biomassa energética, devido à geração de energia elétrica através da queima do bagaço, para uso próprio nas usinas e venda para as concessionárias locais de energia elétrica.

Apesar desse benefício energético, as produções de açúcar, álcool e energia elétrica geram resíduos como a palha, o bagaço e as suas respectivas cinzas, podendo causar problemas ambientais em função da destinação inadequada destes rejeitos.

Por outro lado, a expansão do setor da construção civil, tem proporcionado um considerável aumento no consumo de matérias primas naturais. São empregados em torno de 210 milhões de toneladas de agregados naturais na produção de argamassas e concretos no Brasil, anualmente. Estima-se também que entre 14\% a 50\% dos recursos naturais do planeta são utilizados pelo setor da construção civil ${ }^{(1)}$.

Diante deste crescimento mundial do setor sucro-alcooleiro, aliado à necessidade de alternativas, é de extrema importância a busca por formas para reutilizar esses resíduos, transformando-os de problemas ambientais a produtos de valor comercial. Por ser o setor que mais consome energia e recursos naturais ${ }^{(1)}$, a construção civil é uma excelente opção para se absorver os resíduos da indústria sucro-alcooleira.

Estudos recentes de Frías ${ }^{(2)}$ e Cordeiro ${ }^{(3}$ e ${ }^{4)}$ utilizaram a CBCA com teores de $\mathrm{SiO}_{2}$ acima de 60\%, como adição com propriedades pozolânicas. Verificou-se que a CBCA tem sido utilizada na maior parte dos estudos realizados, como adição, seja em concreto ${ }^{(3,}$ 5), $\operatorname{argamassas}^{(4,6)}$, ou cerâmicas ${ }^{(7)}$.

De acordo com trabalhos recentes $(2,3,5,7,11)$, observa-se uma homogeneidade quanto aos teores de dióxido de silício presentes nas cinzas, e que varia entre 55,97\% a 
96,2\%. A principal diferença entre esses resultados está no estado em que a sílica se encontra (cristalino ou amorfo), sendo o estado amorfo ideal para adição às matrizes cimentíceas, devido à sua elevada reatividade ${ }^{(8)}$.

Diferente da maioria dos estudos realizados com CBCA, neste trabalho é proposta a substituição do agregado miúdo, a areia de referência, pelo resíduo coletado.

\section{MATERIAIS E MÉTODOS}

\subsection{Materiais}

2.1.1. Cimento Portland e Areia de Referência

Neste trabalho, utilizou-se um cimento Portland CP-V ARI RS, da marca Mizu, comercialmente encontrado em Lauro de Freitas, Bahia.

$A$ areia de referência foi selecionada por ter uma granulometria similar à da areia contendo CBCA, sendo oriunda das dunas da região metropolitana de Salvador.

\subsubsection{Areia contendo Cinza do Bagaço da Cana-de-açúcar (CBCA)}

Devido à ausência de um processo de pré-lavagem da cana-de-acúcar na Usina São Luís, localizada na cidade em Maraial (Pernambuco), que forneceu o resíduo, a CBCA é misturada à areia e, por isso, foi utilizada como substituição ao agregado miúdo.

Assim, o resíduo tem como principal componente a areia, oriunda dos canaviais, no processo de coleta. A proporção encontrada foi de, aproximadamente, $97,1 \%$ de areia e $2,9 \%$ de cinzas, em massa.

Com o intuito de reduzir a quantidade de impurezas orgânicas presente na areia contendo $\mathrm{CBCA}$ foi realizado um pré-tratamento com o material sendo colocado em repouso em tanque contendo água para que o bagaço decantasse.

\subsection{Métodos}




\subsubsection{Caracterização das matérias-primas}

Para a caracterização da areia de referência e da areia contendo CBCA foram utilizadas as normas NBR NM 248 ("Agregados - Determinação da composição granulométrica”), a NBR 7219 ("Agregados - Determinação do teor de materiais pulverulentos"), a NBR 9776 ("Agregados - Determinação da massa específica”) e a NBR 7251 ("Agregado em estado solto - Determinação da massa unitária").

A granulometria do cimento foi determinada pelo sedígrafo Horiba CAPA-700 e a sua massa específica foi mensurada pelo método do picnômetro de hélio, utilizando um aparelho Accupyc 1330 V2.01 - Micrometrics.

\subsubsection{Resistência à Tração na Flexão e à Compressão}

A determinação das resistências à compressão axial e à tração na flexão foi realizada segundo a NBR 13279 ("Argamassa para assentamento e revestimento de paredes e tetos - Determinação da resistência á tração na flexão e à compressão").

De acordo com a NBR 13279, devem ser moldados no mínimo três corpos de prova prismáticos para cada idade a ser avaliada, (3, 7, 28 e 63 dias), e com dimensões de $4 \times 4 \times 16 \mathrm{~cm}^{3}$.

As resistências à tração na flexão e à compressão axial são obtidas por meio das eq. $(A)$ e $(B)$, respectivamente.

$$
\begin{gathered}
R_{f}=\frac{1,5 F_{f} L}{40^{3}} \\
R_{c}=\frac{F_{c}}{1600}
\end{gathered}
$$

Onde $R_{f}$ e $R_{c}$ são as resistências à tração na flexão e à compressão axial respectivamente, $F_{f}$ e $F_{c}$ são os esforços aplicados na flexão e na compressão e $L$ é o comprimento dos corpos-de-prova.

\subsubsection{Absorção de Água por Capilaridade}


A determinação da absorção de água por capilaridade foi realizada segundo a NBR 9779 (“Argamassa e concreto endurecidos - Determinação da absorção de água por capilaridade").

A norma determina que sejam moldados pelo menos três corpos-de-prova cilíndricos com dimensões de $5 \mathrm{~cm}$ de diâmetro e $10 \mathrm{~cm}$ de altura.

A absorção capilar é calculada dividindo o aumento de massa pela área da seção transversal da superfície do corpo de prova, representando a massa de água absorvida por metro quadrado da argamassa em contato com a água, em função da raiz quadrada do tempo. O coeficiente de absorção capilar $\left(\mathrm{kg} / \mathrm{m}^{2} \cdot \mathrm{min}^{1 / 2}\right)$, é obtido por meio do coeficiente angular da reta, conforme a Figura 1.

Figura 1. Modelo da curva de absorção capilar de água em função da raiz quadrada do tempo, com determinação do coeficiente de absorção capilar.

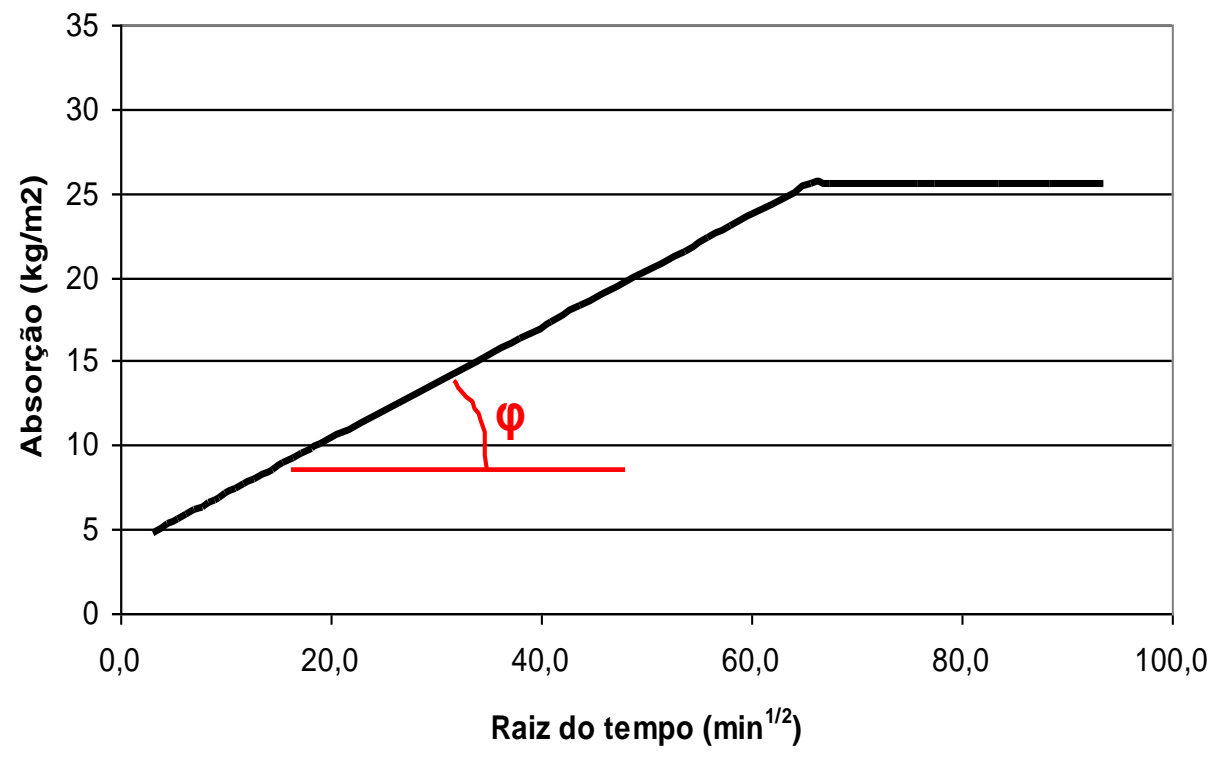

\subsubsection{Determinação da Porosidade e Densidade Aparente}

A determinação da absorção de água, porosidade e massa específica foi realizada de acordo com a NBR 9778 ("Argamassa e concreto endurecidos - Determinação da absorção de água por imersão - Índice de vazios e massa específica”). 
A porosidade $P_{a}$ e densidade aparente $\rho_{a}$ são obtidos pelas eq. (C) e (D), respectivamente.

$$
\begin{aligned}
P_{a} & =\frac{M_{s a t}-M_{s}}{M_{s a t}-M_{i}} x 100 \\
\rho_{a} & =\frac{M_{s}}{M_{s}-M_{i}}
\end{aligned}
$$

Onde $M_{\text {sat }}, M_{s}$ e $M_{i}$ são a massa saturada, massa seca e massa imersa respectivamente.

\section{RESULTADOS E DISCUSSÕES}

\subsection{Caracterização das Matérias-Primas}

Uma etapa fundamental para o desenvolvimento do presente trabalho foi a escolha de um agregado miúdo com características semelhantes às observadas na areia contendo CBCA.

Para tal, foi realizada a caracterização física do agregado contenco CBCA e, posteriormente, comparada à das areias disponíveis.

A areia contendo CBCA e a areia de referência apresentaram curvas granulométricas dentro dos limites utilizáveis superior e inferior, como pode ser visto na Figura 2.

Figura 2. Distribuição granulométrica da areia contendo CBCA e seus limites inferior e superior, de acordo com NBR 7211.

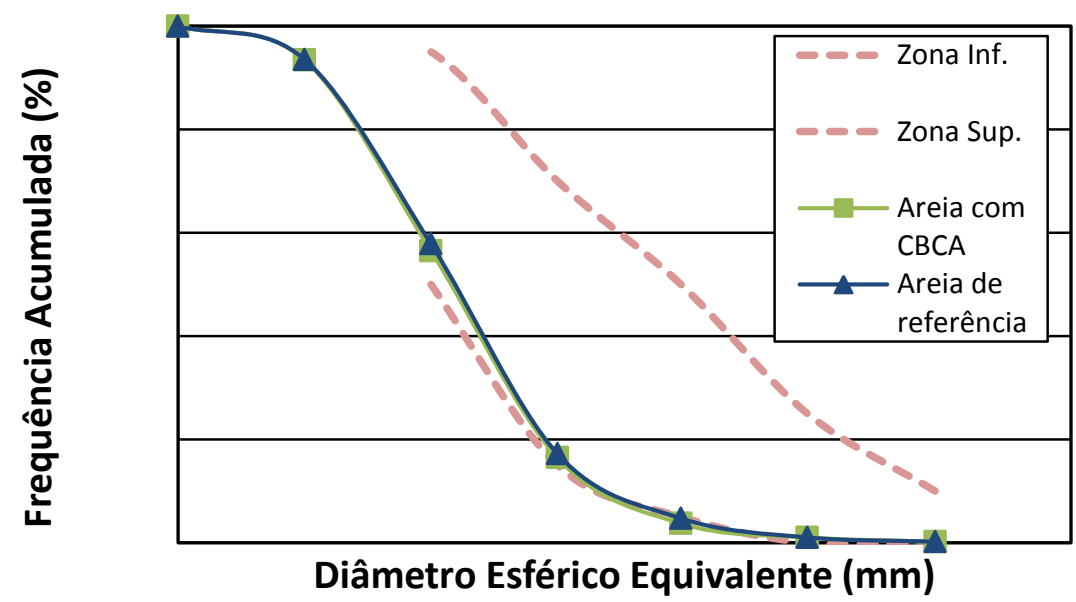


A NBR 7211 especifica quatro zonas de utilização para os agregados miúdos, as zonas utilizável e ótima, superiores e inferiores.

Conforme a Figura 2, verifica-se que a areia contendo CBCA e a areia de referência se encontram na zona utilizável inferior. As demais características físicas da areia de referência podem ser comparadas às da areia contendo CBCA, de acordo com a Tabela 1.

Tabela 1. Propriedades físicas das areias de referência e contendo CBCA.

\begin{tabular}{|c|c|c|}
\hline Propriedades & Areia de Referência & Areia Contendo CBCA \\
\hline Massa Unitária $\left(\mathrm{kg} / \mathrm{dm}^{3}\right)$ & 1,67 & 1,65 \\
\hline $\begin{array}{c}\text { Massa Específica } \\
\left(\mathrm{kg} / \mathrm{dm}^{3}\right)\end{array}$ & 2,60 & 2,55 \\
\hline Módulo de Finura & 1,75 & 1,71 \\
\hline $\begin{array}{c}\text { Dimensão Máxima do } \\
\text { Agregado }(\mathrm{mm})\end{array}$ & 1,18 & 1,18 \\
\hline
\end{tabular}

O cimento apresentou curva granulométrica dentro do especificado pela NBR 5732. De acordo com a figura 3 pode-se verificar que a percentagem retida na peneira 75 $\mu \mathrm{m}$ é de apenas $1,5 \%$, abaixo do limite estabelecido pela norma (12\%). O cimento apresentou massa unitária igual a $1,00 \mathrm{~kg} / \mathrm{dm}^{3}$, massa específica de $3,17 \mathrm{~kg} / \mathrm{dm}^{3}$ e área superficial específica BET igual a $0,8924 \mathrm{~m}^{2} / \mathrm{g}$. 
Figura 3. Distribuição de tamanho de grãos do cimento Portland CP V ARI RS, determinada por meio do Sedígrafo.

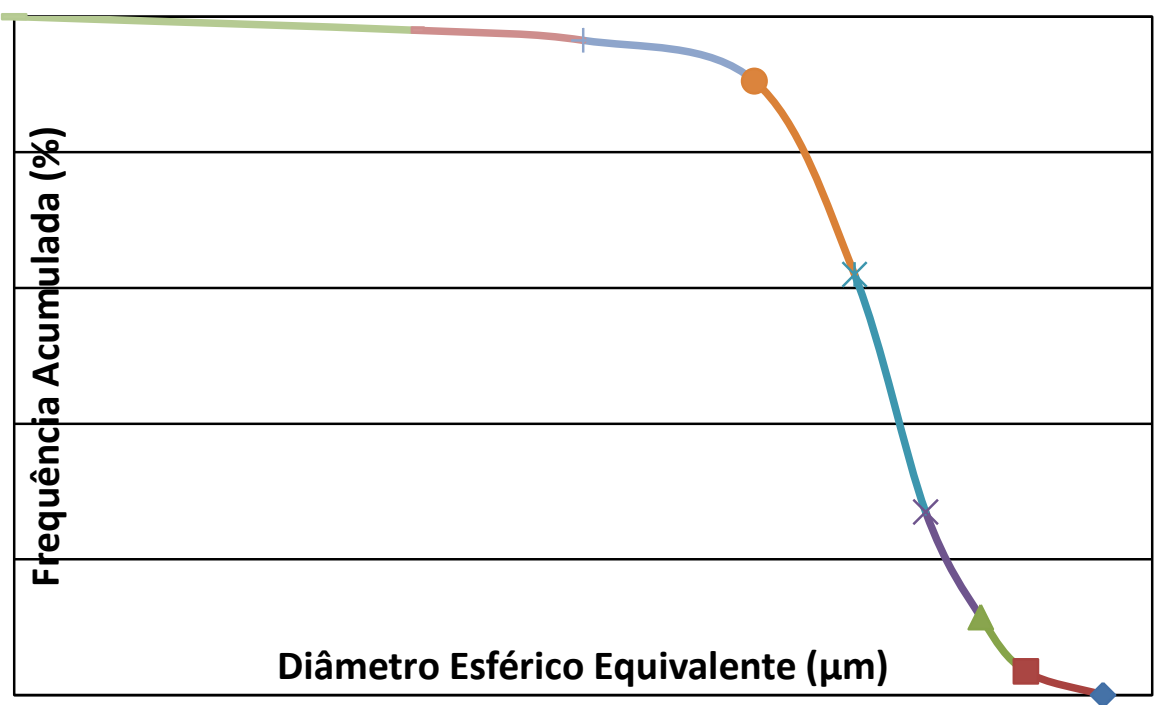

\subsection{Determinação da Porosidade e Densidade Aparentes}

As figuras 4 e 5 mostram a evolução da porosidade e da densidade aparente respectivamente, em função do teor de substituição da areia de referência pela areia contendo CBCA.

Como a massa específica da areia contendo CBCA é menor do que a massa específica da areia de referência e às dificuldades de moldagem devido ao aumento do teor de substituição da areia, houve uma diminuição da densidade aparente e aumento da porosidade. A dificuldade nas moldagens ocorreu devido ao fato da dimensão das partículas da CBCA ser muito pequena (em torno de $2,7 \mu \mathrm{m}^{(3)}$ ) e à presença de bagaço da cana de açúcar. Apesar da finura das partículas promover um aumento da compacidade da argamassa, esta tende a perder trabalhabilidade. 
Figura 4. Porosidade aparente das argamassas após 28 dias para os diferentes teores de substituição da areia referencial pela areia contendo CBCA.

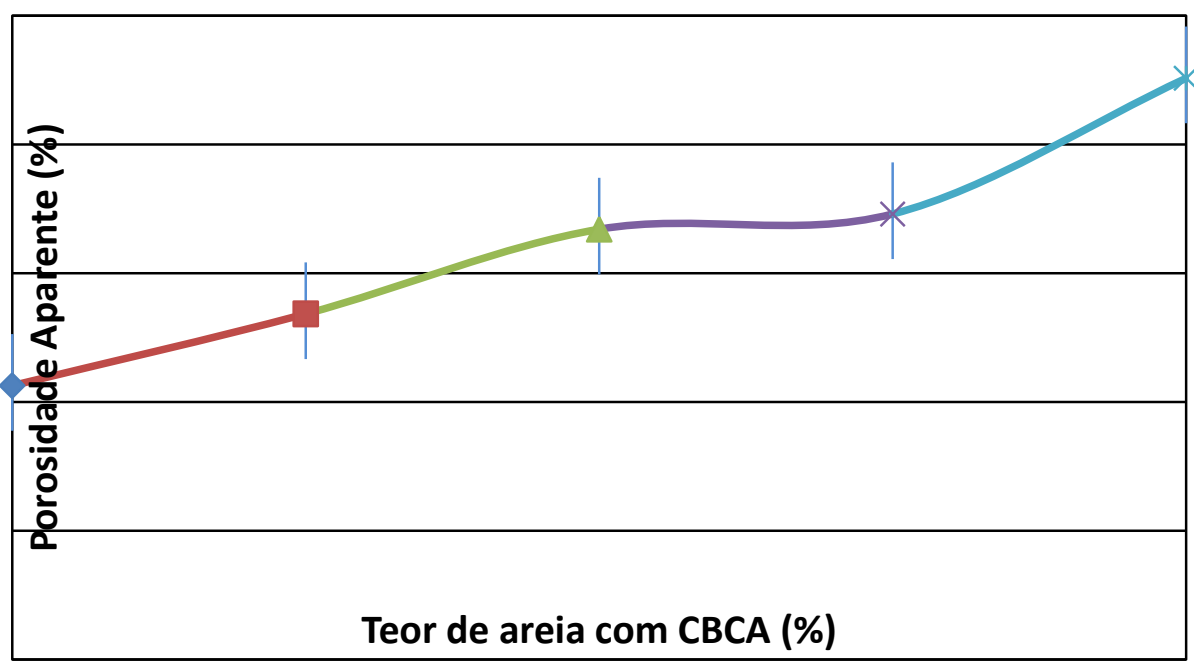

Figura 5. Densidade aparente das argamassas após 28 dias para os diferentes teores de substituição da areia referencial pela areia contendo CBCA

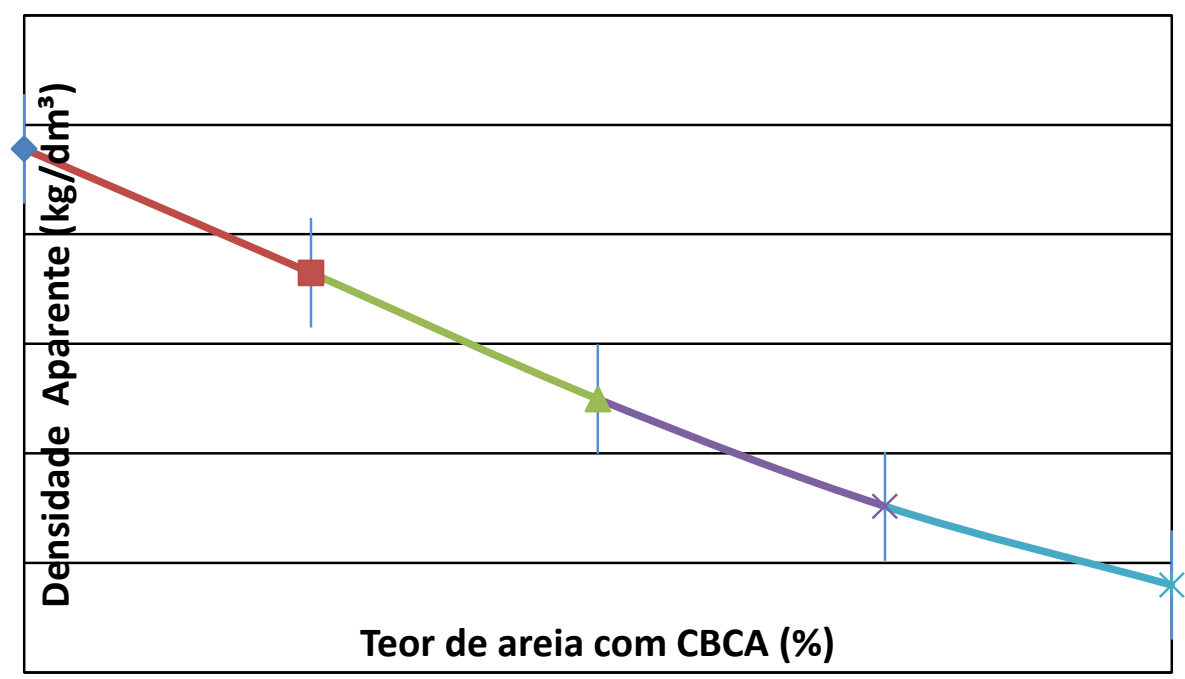

\subsection{Absorção de Água por Capilaridade}

Pode-se observar um aumento significativo na absorção de água por capilaridade, em função do aumento do teor de areia contendo CBCA. Isso é devido à presença das 
cinzas que têm uma elevada área superficial, e à presença do bagaço da cana. $\mathrm{O}$ bagaço tem alta absorção de água, contribuindo para a ascensão capilar. Além disso, a elevada finura da CBCA , associada a uma possível atividade pozolânica deste material, fazem com que este haja como um fíller e refine a microestrutura dos poros da matriz, aumentando, assim, a sucção capilar.

A variação dos coeficientes de absorção para os diferentes teores de substituição podem ser observados na figura 6 .

Figura 6. Coeficiente de absorção de água por capilaridade após 28 dias para os diferentes teores de substituição da areia referencial pela areia contendo CBCA.

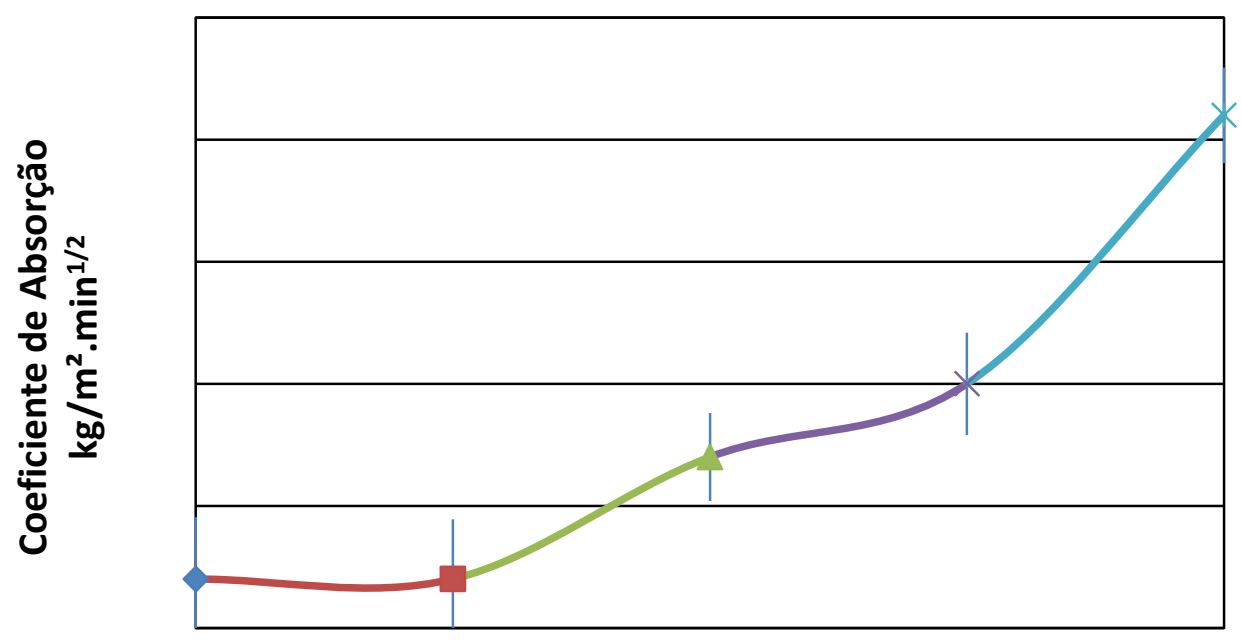

Teor de areia com CBCA (\%)

\subsection{Propriedades Mecânicas}

Os resultados das resistências à tração na flexão e à compressão nos corpos-deprova de argamassa para os diferentes teores de substituição da areia comum pela areia contendo CBCA podem ser vistos na Figura 7 e na Figura 8. 
Figura 7. Resistência à compressão axial das idades de 3, 7, 28, 63 e 91 dias para os diferentes teores de substituição da areia comum pela areia com CBCA.

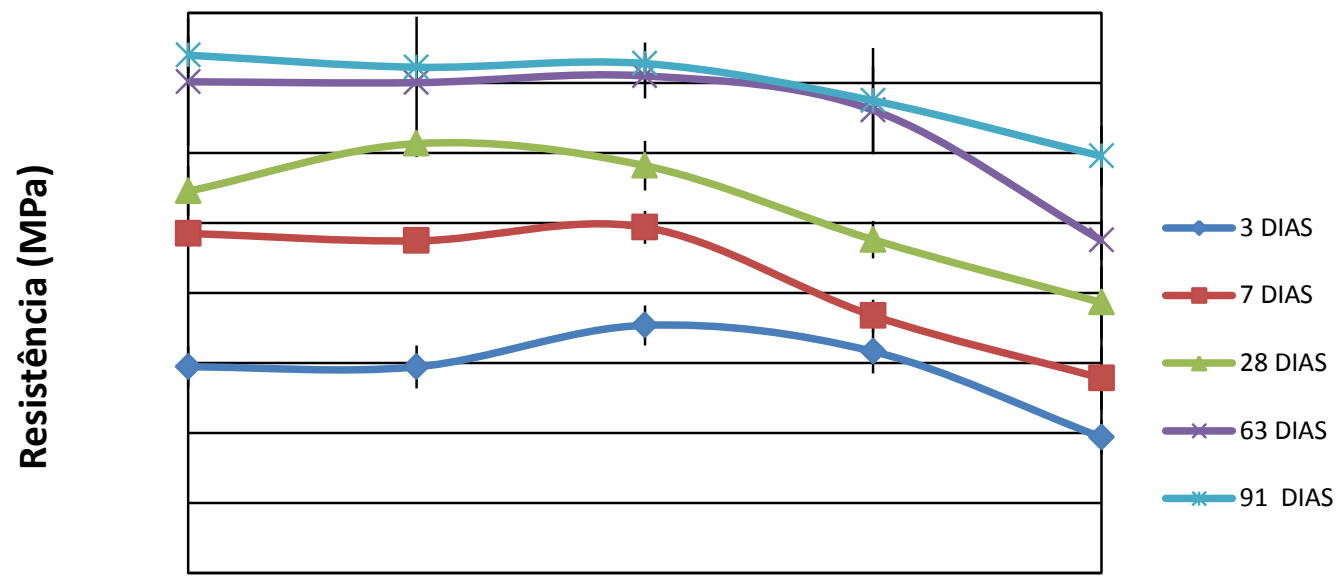

Teor de areia com CBCA (\%)

Figura 8. Resistência à tração na flexão das idades de 3, 7, 28, 63 e 91 dias para os diferentes teores de substituição da areia comum pela areia com CBCA.

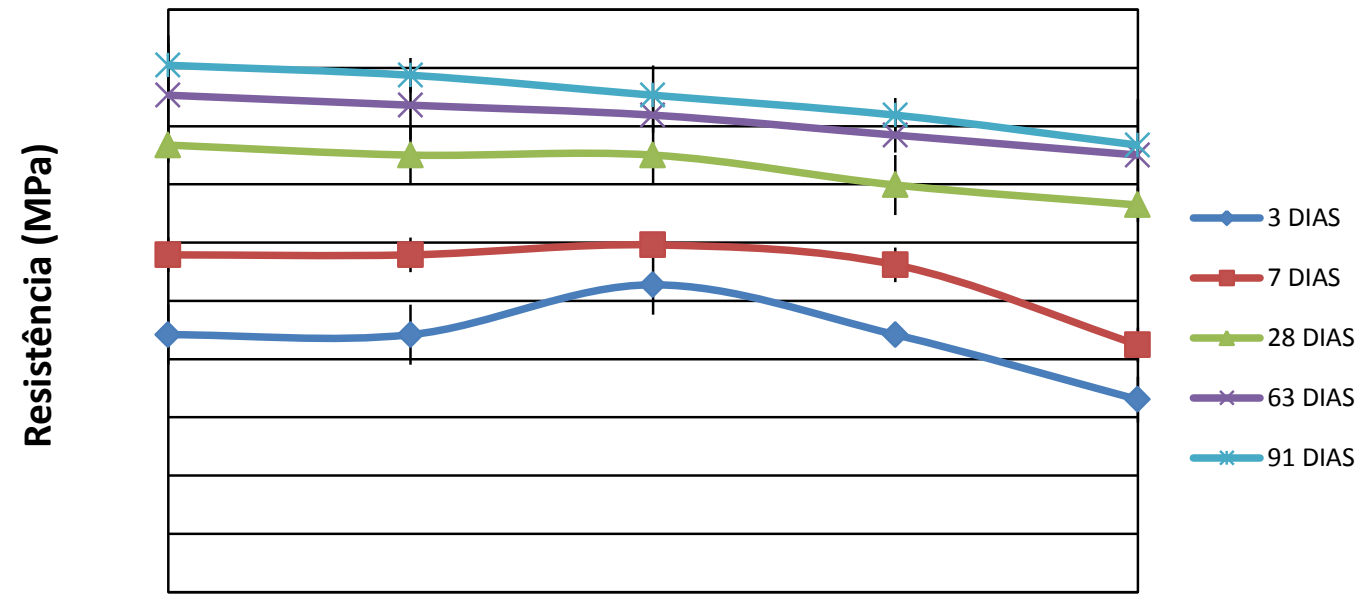

Teor de areia com CBCA (\%)

Pelos resultados obtidos pode-se observar um aumento na resistência à compressão para os corpos-de-prova contendo até 50\% de areia contendo CBCA. Para quantidades superiores de adição houve uma queda na resistência. O comportamento dos 
corpos-de-prova quanto à resistência à tração na flexão mostrou uma queda em função do teor de areia substituído.

Estudos anteriores mostraram que há um aumento de resistência para adição da CBCA em até $15 \%^{(6,9,10)}$. Lima ${ }^{(11)}$ verificou que adições de até $8 \%$ da CBCA não afetam a resistência mecânica dos blocos, mas as de argamassas com o mesmo percentual de adição obtêm uma melhor performance estrutural.

Acredita-se que a queda de resistência, ocorreu devido à presença de bagaço no resíduo, e restringindo o estudo entre $25 \%$ e $50 \%$, será possível identificar a porcentagem ideal de substituição da areia comum pela areia contendo CBCA.

\section{CONCLUSÕES}

Após a análise dos resultados apresentados, pode-se concluir que:

- A substituição parcial do agregado miúdo de referência pelo agregado contendo CBCA afetou significantemente na argamassa, havendo uma diminuição da densidade aparente e aumento da porosidade.

- Houve um aumento significativo na absorção de água por capilaridade, em função do aumento do teor de areia contendo CBCA.

- Os resultados obtidos para a resistência mecânica, com teores de substituição do agregado até $50 \%$ foram melhores do que o teor de referência e demais teores, atestando a viabilidade técnica do uso deste rejeito a matrizes cimentícias.

\section{REFERÊNCIAS}

JOHN, V. M. Reciclagem de resíduos na construção civil: Contribuição para metodologia de pesquisa e desenvolvimento. 2000. 113f. Tese (Livre Docência) Escola Politécnica, Universidade de São Paulo, São Paulo, 2000.

FRÍAS, M.; VILLAR, E.; SAVASTANO, H. Brazilian sugar cane bagasse ashes from the cogeneration industry as active pozzolans for cement manufacture. Cement \& Concrete Composites, v. 33, n. 4, p. 490-496, 2011.

CORDEIRO, G. C.; TOLEDO FILHO, R. D.; TAVARES, L. M.; FAIRBAIRN, E. M. R. Experimental characterization of binary and ternary blendde-cement concretes containing 
ultrafine residual Rice husk and sugar cane bagasse ashes. Construction and Building Materials, v. 29, p. 641-646, 2012.

CORDEIRO, G. C.; TOLEDO FILHO, R. D.; FAIRBAIRN, E. M. R. Effect of calcination temperature of the pozzolanic activity of sugar bagasse ash. Construction and Building Materials, v. 23, n. 10, p. 3301-3303, 2009.

MORALES, E. V.; COCIÑA, E. V.; FRÍAS, M.; SANTOS, S. F.; SAVASTANO JR., H. Effects of calcining conditions on the microstructure of sugar cane waste ashes (SCWA): Influence in the pozzolanic activation. Cement \& Concrete Composites, v. 31, n. 1, p. 2228, 2009.

PAULA, M. O.; TINÔCO, I. F. F.; RODRIGUES, C. S.; SILVA, N.; SOUZA, C. F. Potencial da cinza do bagaço da cana-de-açúcar como material de substituição parcial de cimento Portland. Revista Brasileira de Engenharia Agrícola e Ambiental, v.13, n.3, p. 353-357, 2009.

BORLINI, P. C.; MENDONÇA, J. L. C. C.; VIEIRA, C. M. F.; MONTEIRO, S. N. Influência da Temperatura de Sinterização nas Propriedades Físicas, Mecânicas e Microestruturais de Cerâmica Vermelha Incorporada com Cinza de Bagaço de Cana de Açúcar. Revista Matéria, v. 11, n. 4, p. 435-443, 2006.

NEVILLE, A. M. Propriedades do Concreto. 2. ed. São Paulo: Pini. 1997. 828p.

FAIRBAIRN, E.M.R.; AMERICANO, B.B.; CORDEIRO, G.C.; PAULA, T.P.; FILHO, R.D.T.; SILVOSO, M.M. Cement replacement by sugar cane bagasse ash: $\mathrm{CO}_{2}$ emissions reduction and potencial for carbon credits. Journal of Enviromental Management, v. 91, n. 9, p. 1864-1871, 2010.

FREITAS, E.G.A.; RODRIGUES, E.H.V.; ARAUJO, R.C.L.; FAY, I. Efeito da adição de cinzas de bagaço de cana na resistência à compressão de argamassas normal. In: CONGRESSO BRASILEIRO DE ENGENHARIA AGRíCOLA, 27, Poços de Caldas, 1998. Anais ... Lavras: Sociedade Brasileira de Engenharia Agrícola, v. 4, p. 219-221, 1998.

LIMA, S.A.; VARUM, H.; SALES, A.; NETO, V.F. Analysis of the mechanical properties of compressed earth block masonry using the sugarcane bagasse ash. Construction and Building Materials, v. 35, p. 829-837, 2012 